\title{
Challenges of microarray applications for microbial detection and gene expression profiling in food
}

\author{
Yanhong Liư ${ }^{1 *}$, Yan Wang ${ }^{2}$ and Jie Gang ${ }^{3}$
}

${ }^{1}$ Molecular Characterization of Foodborne Pathogen Research Unit, Eastern Regional Research Center, 600 East Mermaid Lane,Wyndmoor, PA 19038, USA

${ }^{2}$ Science Research Center, Harbin Institute of Technology, Harbin, Heilongjiang 150001, P. R. China

${ }^{3}$ Food Engineering Department, College of Life Sciences, Dalian Nationalities University, Dalian, 116600, P. R. China

\begin{abstract}
Microarrays are a high throughput technology used in molecular biology. The different types of microarrays have been applied to clinical and environmental microbiology, microbial ecology, human, veterinary, and plant diagnostics. Since multiple genes can be analyzed simultaneously, this technology has been extended to food microbiology for detection and gene expression analyses of food-borne pathogens. Although this technique has multiple applications, microarray technology presently has low sensitivity and also suffers from problems such as reproducibility and reliability. This paper focuses on microarray applications for microbial detection and gene expression profiling of food-borne pathogens including some of the challenges and key issues such as target nucleic acid isolation and selection of target DNA sequences.
\end{abstract}

Keywords: Microarray; Real-time PCR; Detection; Gene expression; Food

\section{Introduction}

Microarray technologies that have been developed since 1995 are very powerful tools to simultaneously analyze a large number of genes or target DNA sequences. Whole-genome sequencing of a number of food-borne pathogens including E. coli, Salmonella, spp., and Listeria, spp., has allowed the construction of microarray chips for use in food microbiology. Microarray applications for food-borne pathogen detection, food quality, and food safety have been extensively reviewed [1-5]. The main applications of microarray technology in foods are i) analysis of bacterial gene expression, and ii) detection of specific microorganisms. However, there is no review covering microarray applications in both aspects. This review focuses on current applications of microarray technologies (mainly from our laboratory) in both microbial detection and gene expression in food.

The most common microarray application is differential gene expression analyses. The first step in these types of analyses is extraction of RNA from cells. In bacteria, total RNA is usually used as the starting material, although protocols for purification of bacterial mRNA have been developed [6]. Briefly, RNA from two samples (control vs. treated) are reverse transcribed to cDNA and then labeled with different fluorescence dyes either during or after reverse transcription. The most commonly used labels include the fluorophors, $\mathrm{Cy} 3$ and Cy5. The different fluorescent labeled cDNA samples (control vs. treated) are mixed and hybridized to a microarray chip containing oligonucleotides or PCR amplified DNA fragments covering the entire genome of a bacterial pathogen. After washing off the nonspecific signals, the microarray chip is scanned using a microarray scanner and the fluorescence signals of each spot on the microarray are quantified (Figure 1). After intensive data normalization and statistical analysis, the ratio of the intensities of both dyes (e.g., $\mathrm{Cy} 3 / \mathrm{Cy} 5$ and $\mathrm{Cy} 5 / \mathrm{Cy} 3)$ reflects the relative expression levels for both control and treated samples. The usage of two dyes allows for the quantitative comparison of two samples on a single chip. To avoid dye bias resulting from differences in the incorporation efficiency of the fluorescent dyes, a dye-swamp experiment representing a technical replicate of microarray chip in which the same samples are hybridized but with a reverse labeling is usually performed [7]. Dye swap with true biological replicates achieves the same goals but with greater statistical power. In addition to two channel arrays, one-channel arrays, e. g. Affymatrix and Illumina are also very popular and commonly used in academic and industry setting.

Microarrays can be used to detect whether a specific sequence is present in a sample. The detection microarray chips can cover an entire genome, or a subset of genes from several genomes. However, the most commonly used microarrays for detection of microorganisms contain a limited number of signature sequences in a microorganism and are used for species identification or differentiation among strains. Procedures using microarrays for detection start with purification of genomic DNA from target cells, followed by PCR amplification or whole genome amplification, and then labeling with a fluorescent dye. For this type of analysis, only one fluorescence dye is needed because the assay is designed to detect whether or not a sequence is present in the sample (Figure 2). After hybridization and washing, the microarray chips are scanned using a microarray scanner and the fluorescence signals are quantified.

Microarrays possess considerable advantages and potential for the detection and characterization of pathogenic microorganisms. For example, multiple microorganisms can be detected simultaneously from a sample, and the presence of virulence genes and antibiotic resistance genes carried by a pathogen can also be detected. Various types of microarrays have been developed and evaluated for pathogen detection in food and environmental samples and for biodefense applications [8,9]. Genetic markers used for microarray-based

*Corresponding author: Yanhong Liu, Molecular Characterization of Foodborne Pathogen Research Unit, Eastern Regional Research Center, 600 East Mermaid Lane, Wyndmoor, PA 19038, Tel.215-233-6587 ; Fax : 215-233-6581; E-mail: yanhong.liu@ars.usda.gov

Received April 29, 2011; Accepted June 18, 2011; Published June 20, 2011

Citation: Liu Y, Wang Y, Gang J (2011) Challenges of microarray applications for microbial detection and gene expression profiling in food. J Microbial Biochem Technol S2:001. doi:10.4172/1948-5948.S2-001

Copyright: @ 2011 Liu Y, et al. This is an open-access article distributed under the terms of the Creative Commons Attribution License, which permits unrestricted use, distribution, and reproduction in any medium, provided the original author and source are credited 
microbial detection include but are not limited to housekeeping genes such as 16S-23S rDNA [10], gyrB genes [11], and virulence genes [12]. Microarray techniques have been used to distinguish among different bacterial genera [13], as well as among different strains within the same species such as Listeria monocytogenes [14,15] and Salmonella serovars [16]. Some innovative approaches in detection arrays also include: (a) simultaneous detection of host genes for pathogen identification and virulence/resistance genes for assessment of host potential to develop an illness, (b) horizontal transfer of genetic markers among related and not-related bacterial strains.

Although microarrays have been successfully used for microbial detection in pure-culture studies [17], there are technical difficulties when microarrays are applied to real food samples. Two main issues are discussed in this review: isolation of a sufficient amount of target genomic DNA and the selection of DNA probe sequences for the detection chips.

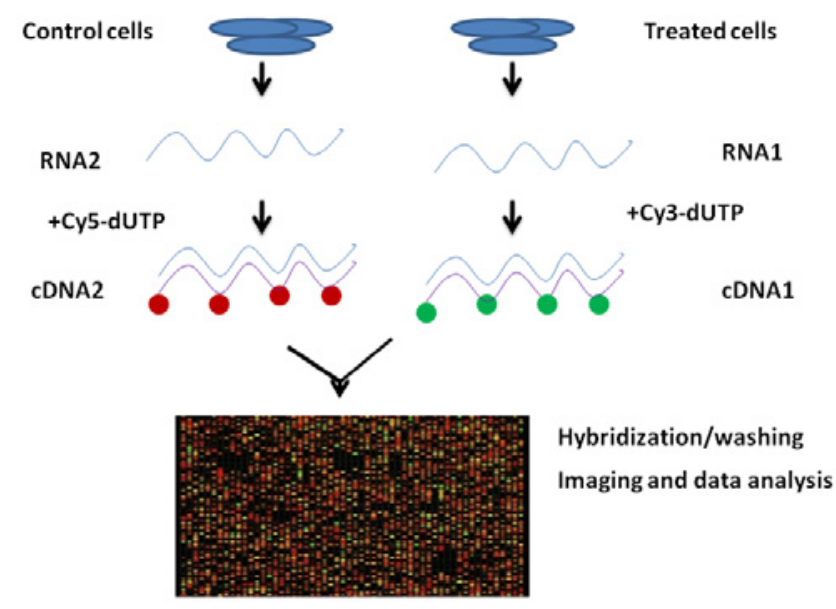

Figure 1: Schematic representation of gene expression array.

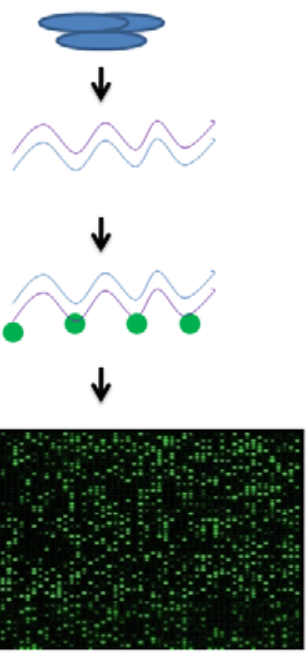

Cells

DNA extraction and amplification

Amplification and Labeling (Cy3-or Cy5-dUTP)

Hybridization/washing Imaging and data analysis

Figure 2: Schematic representation of detection array

\section{Isolation of sufficient target genomic DNA from food}

A significant challenge in the development of methods for microbial detection in food is the need to detect and characterize a small number of target microorganism(s) in a large sample volume, often with a background flora consisting of similar microorganisms and the presence of interfering food matrix material. Microarrays require a relatively large amount (microgram levels) of DNA, but the fact that food samples usually contain only small numbers of pathogens makes it very difficult to isolate enough genomic DNA. Traditional cultural enrichments of microorganisms in food samples are usually necessary [18].

One way to increase the yield of target DNA is selective amplification of the specific sequences. If the probes on the chip represent a specific locus or a few loci of the gene sequences, target sequences covering the entire locus can be amplified by the PCR. Hybridization of the amplified PCR products to the microarrays will result in greater specificity and sensitivity. For example, the entire $\mathrm{O}$-antigen gene cluster sequences of different $E$. coli serogroups were amplified by long PCR and labeled before hybridizing the labeled PCR product to microarrays containing oligonucleotides (35-mers) of the specific O-antigen gene clusters [19].

If the probes on the chip represent a number of sequences from different loci, whole genome amplification methods can be used to amplify the target sequences before applying to microarrays. Multiple displacement amplification (MDA) is an isothermal amplification method that uses the bacteriophage Phi29 DNA polymerase and random primers [20]. The strand-displacement synthesis yielded about $20-30 \mu \mathrm{g}$ of product ( $>10 \mathrm{~kb}$ in length) from as few as 1-10 copies of human genomic DNA [21]. MDA can be performed directly on biological samples and has been applied to amplify bacteria in water [22]. Although MDA permits microbial detection in a food that contains low levels of bacterial DNA, it may not increase the specificity of the microarray assays since the whole genome, including the selected target sequences on the chip, is amplified. In addition, some loci may be preferentially amplified by MDA while other loci have low amplification. Recently, a new linear whole genome amplification method (NuGEN Ovation Whole Genome Amplification) that only requires $10 \mathrm{ng}$ of input genomic DNA was developed. The ability to linearly amplify genomic DNA from limited amounts of template DNA offers the possibility for microbial detection in real food matrices.

\section{DNA probe sequences for microbial detection}

Microbial detection is based on the ability of a microarray to identify sequences present in the target organism. Typically, microarrays used for detection/characterization of food-borne pathogens contain less than a few hundred probes with well defined target sequences. This is in contrast to gene expression microarrays that often contain the probes representing all genes/loci of bacteria. Since food samples may contain a multitude of non-target genomes, the detection microarrays must contain the sequences that are unique to each microorganism (i.e., signature sequences) with respect to all non-target genomes. Such signature sequences (probes) provide information regarding the identification of the microorganism or its important characteristics. It is a challenge to identify the signature sequences of each microorganism, since a majority of bacterial genome sequences are conserved. The design of the signature sequences (probes) requires identification of unique target sequences through genomic database searches and multiple alignment analysis, and then the design of oligoprobes to represent these sequences on the array. A number of computer programs have been developed for this bioinformatic task. 
For bacteria in which the whole genome sequence is not available, gene clusters from each bacterium can be sequenced and compared to identify the sequences that are unique to each bacterium. For example, the O-antigen gene clusters of different E. coli serogoups were sequenced and the OligoArraySelector program [23] was used to select the probe sequences unique to different $E$. coli serogroups [19].

For microorganisms for which the whole genome sequence has been determined, several software packages are available to identify unique sequences (biomarkers representing each microorganism). For example, a multigenome software package named Tool for Oligonucleotide Fingerprint Identification (TOFI) was developed and has been used to identify DNA fingerprints in Bacillus anthracis, Yersinia pestis, Francisella tularensis and Burkholderia mallei and Burkholderia pseudomallei genomes. Furthermore, the accuracy of these in silico DNA fingerprints was validated by microarray hybridization experiments [24-27]. Targeting these DNA fingerprints greatly increased the specificity of the microarray assays.

\section{A case study: microarray application in $E$. coli $O$ antigen typing}

E. coli serotyping is conventionally performed by agglutination reactions using antisera raised in rabbits against the 179 different $\mathrm{O}$ standard references strains. However, traditional serotyping is laborious, time consuming, and often generates equivocal results due to cross-reactions among different serogroups. Furthermore, the antisera for serotyping can only be generated by specialized laboratories with animal facilities. Rapid molecular methods for identifying different $E$. coli serogroups are needed. The $\mathrm{O}$ antigen, which contains many repeats of an oligosaccharide unit ( $\mathrm{O}$ unit) is present in the outer membrane of Gram-negative bacteria and contributes the major antigenic variability to the cell surface. The genes involved in the biosynthesis of $\mathrm{O}$ antigens in $E$. coli are located in the O-antigen gene cluster and are flanked by the galF and gnd genes on the E. coli chromosome. A number of $E$. coli $\mathrm{O}$-antigen gene clusters have been sequenced and the genes were annotated (28-32). Several genes in the clusters, in particular the $w z x(\mathrm{O}$ antigen flippase) and $w z y$ (O antigen polymerase) genes, show relatively low similarity among different $E$. coli serogroups, and PCR primers targeting the $w z x$ and $w z y$ genes have been used to develop serogroupspecific PCR assays [28-31]. However, since each primer is specific for the respective $\mathrm{O}$-antigen gene cluster genes, $\mathrm{PCR}$ assays targeting each of the serogroups need to be performed to identify the E. coli strain. Therefore, an assay for parallel detection of multiple serogroups in a single platform would be useful. To this end, DNA microarrays were developed for rapid identification of different serogroups of $E$. coli in a single platform. Oligonucleotides, as well as PCR products from genes in the $\mathrm{O}$-antigen gene clusters of $E$. coli serogroups O7, O104, O111, and O157 were spotted onto glass slides. This was followed by hybridization with labeled long PCR products of the entire $\mathrm{O}$-antigen genes clusters of these serogroups. Results demonstrated that microarrays consisting of either oligonucleotides or PCR products generated specific signals for each serogroup [19]. Since many O antigen gene clusters have been sequenced, targets specific for the sequenced gene clusters can be selected and placed onto the typing array, and there is the potential to expand the DNA array to contain target sequences for all of the E. coli serogroups. This research highlights are the importance of microarray technology in pathogen typing.

\section{Gene expression microarray applications in food matrices}

The availability of whole genome sequence information for several food-borne pathogens has paved the way for global analyses of microbial adaptation to various environments [33]. For example, microarrays were used to study the responses of L. monocytogenes and B. subtilis to cold stress, and a number of genes that are differentially expressed at low temperatures were identified [34,35]. However, genomic studies of food-borne pathogens in a real food matrix are generally lacking.

There are some crucial challenges to study gene expression of foodborne pathogens in food using microarrays. For example, bacteria usually are present in food in low numbers; therefore, RNA from bacterial cells is not sufficient for target labeling and hybridization for microarrays. Large numbers of bacterial cells must be used to artificially contaminate food to achieve enough RNA. Prior to hybridization, some type of signal amplification is needed. One method, termed whole-community RNA amplification (WCRA) has been developed to provide sufficient amounts of prokaryotic RNAs from environmental samples for microarray analysis [36]. In this approach, a T7 RNA promoter sequence is attached to fusion primers (six to nine random nucleotides), which is then used for reverse transcription of RNA to cDNA. The synthesized cDNA were in turn used for linear RNA amplification with T7 RNA polymerase. About 1200- to 1800-fold amplification was obtained from 10 to $100 \mathrm{ng}$ RNA templates, and very representative detection was obtained with 50 to $100 \mathrm{ng}$ total RNA [36].

\section{Separation of bacteria from food matrices}

Another challenge is to separate bacterial pathogens from food matrices. Differential separation and centrifugation are effective ways to separate bacteria from milk. We also developed a system using dialysis tubing containing a high level $\left(10^{9} \mathrm{cfu} / \mathrm{ml}\right)$ of L. monocytogenes to study gene expression in milk. Dialysis tubing with a high molecular weight cutoff ( 1 million Daltons) was placed in milk. The high cutoff allows the small milk components to travel freely, while keeping the bacteria inside the tubing. Using this system, a sufficient quantity of RNA was isolated from L. monocytogenes and used for microarray experiments to identify the genes expressed in milk [37]. In addition, a filtration step combined with immunomagnetic separation (IMS) has been used to successfully separate Listeria monocytogenes from salmon matrix $[38,39]$. Bacterial RNA has been isolated successfully from other solid foods such as liver pates and cheese [40,41]. Furthermore, the physiological properties of bacteria can be altered by sampling processing time. In E. coli, rapid changes in levels of specific mRNAs have been observed as a result of changing environmental conditions [42].

Microarrays have been used to study how food-borne pathogens survive and grow in food. For example, microarrays were used to monitor the gene expression profiles of L. monocytogences strain F2365 in Ultra-High Temperature (UHT) processed skim milk. Total RNA was isolated from strain F2365 in UHT skim milk after 24 hours at $4^{\circ} \mathrm{C}$, reverse transcribed, labeled with fluorescent dyes, and hybridized to oligonucleotide (35-mers) microarray chips containing the whole genome of L. monocytogenes strain F2365 [43]. The electrochemically synthesized oligonucleotide microarrays used in this study [37] was Customarray $^{\text {nat }} 12 \mathrm{~K}$ arrays (Combimatrix, Mukilteo, WA). The arrays were constructed to include 35-mer oligonucleotides representing the 2847 L. monocytogenes open reading frames (ORFs). Compared to the spotted microarrays, these in situ custom synthesized microarrays have the advantages of low cost, accuracy, flexibility, and reusability [44]. Genes that were up- (26 genes) and down-regulated (14 genes) in UHT pasteurized skim milk were identified. Furthermore, the gene expression changes determined by microarray assays were confirmed by real-time RT-PCR analyses [37]. The identified genes will be good 
candidates for gene knock-out studies to identify the role of the genes. Understanding how bacteria survive in different food systems may help food processors develop effective preservation strategies to better manage pathogens in food. Since food systems are complex with different nutritional components, bacterial pathogens in different foods may grow differently. This study can be extended to evaluate the gene expression profiling of different bacterial pathogens in different food matrices. Eventually, this study will contribute to detailed and fundamental understanding of the mechanisms of bacterial growth and survival in food. Other food matrixes used for bacterial gene expression included lettuce leaves and sourdoughs $[45,46]$.

In addition to studying food-borne pathogens, microarray approaches have been used to study probiotic microbes in food such as Lactobacillis acidophilus in skim milk [47]. Probiotics are live microorganisms that confer a health benefit to the host when administered in adequate amounts. Probiotics can also control undesireable microorganisms in food animals. Gene expression profiles were studied during growth of Lactobacillus helveticu in milk [48] versus a rich culture medium. Moreover, proteomic approaches were used to identify protein signatures of Lactococcus lactis in milk [49]. Lactobacillus sakei genes that were induced during meat fermentation have also been identified [50]. Survival of probiotic strains during storage is a key issue for the food industry. Information from these studies could help in understanding how the probiotic bacteria survive in food and to provide insights on how to improve survival of these bacteria in food.

\section{Microarray applications in food processing and interventions}

High pressure processing (HPP) has been introduced as an alternative to heat and other traditional food preservation methods because it does not adversely affect the sensory properties or the freshness attributes of certain foods. Several research groups investigated the mechanism of action of high pressure against bacterial cells using microarrays [51-53]. Since different bacteria and different pressure conditions have been used, results are difficult to compare. Microarrays were used to analyze the transcriptional profiling of $E$. coli grown at 30 and $50 \mathrm{MPa}$ [52]. Both heat and cold stress responses were induced simultaneously by the elevated pressure. In addition, an E. coli mutant, with a deletion in the hns gene encoding a DNA binding protein exhibited great pressure sensitivity [52]. Sublethal pressure (100 $\mathrm{MPa}, 15 \mathrm{~min}$ ) was used to study the transcriptional profiling of E.coli O157:H7 [53]. High pressure affected the transcription of many genes including those involved in stress responses, the thiol-disulfide redox system, and Fe-S cluster assembly. Microarrays were used to study the differential gene expression of $L$. monocytogenes strain S2542 during high hydrostatic pressure (400 MPa and $600 \mathrm{MPa}, 5 \mathrm{~min}$ ) [51]. HPP induced increased expression of genes associated with DNA repair mechanisms, transcription and translation protein complexes, the septal ring, the general protein translocase system, flagella assemblage and chemotanis, and lipid and peptidoglycan biosynthetic pathways. On the other hand, HPP suppressed a wide range of genes associated with energy production and conversion and carbohydrate metabolism and virulence-associated genes [51].

In L. monocytogenes, microarrays have been used to determine the role of the $c t s R$ gene in resistance to high pressure. The ctsR gene encodes for a class III heat shock protein which is the first gene of the four-gene $c l p C$ operon. Under normal conditions, the CtsR protein negatively regulates the $c l p C, c l p P$ and $c l p E$ genes by binding specifically to the regulatory regions of these genes [54]. Under stressed conditions, the
CtsR protein was degraded by the ClpCP protease [55]. CtsR has been shown to be related to high pressure since several pressure-tolerant mutants contained mutations in this gene [56-58]. A cts $R$ mutant (AK01) of L. monocytogenes Scott A containing a glycine deletion was non-motile and showed greater resistance to high pressure, heat, acid, and $\mathrm{H}_{2} \mathrm{O}_{2}$ than the wild type [57]. The L. monocytogenes Scott A ctsR mutant (2-1) exhibited a 100-fold higher level of variability than the wild type when exposed to $450 \mathrm{MPa}$. The mutant 2-1 had a deletion in the $c t s R$ gene that resulted in truncation of CtsR of 20 amino acids in CtsR protein [59]. The N-terminal truncation of CtsR lacked the DNA binding and heat sensing domains. Compared to the wild type, the mutant 2-1 showed increased cell length and had no flagella (Figure 3). In addition, it was heat resistant, and sensitive to nisin [59]. However, the mechanism of its survival under high pressure is unclear. Microarrays were used to study the gene expression of mutant 2-1 under high pressure. Total RNA was isolated from the pressure-treated (450 Mpa, 3 minutes) cts $\mathrm{R}$ mutant 2-1, reverse transcribed, labeled with fluorescent dyes, and hybridized to commercial oligonucleotide (35-mers) microarray chips representing the whole genome of $L$. monocytogenes. The gene expression changes determined by microarray assays were confirmed by the real-time RT-PCR analyses. Compared to the pressure-treated L. monocytogenes Scott A wild type, 19 genes were up-regulated ( $>2$-fold increase) in the ctsR deletion mutant whereas 57 genes were down-regulated $(<-2$-fold decrease) [60]. The up-regulated genes included genes encoding for a transcriptional regulator, ATPdependent Clp protease, putative accessory gene regulator proteins $\mathrm{B}$ and $\mathrm{D}$, transport and binding proteins, phosphotransferase system (PTS) fructose-specific enzyme IIABC components, protein synthesis, and hypothetical proteins. The down-regulated genes included genes that encode for PTS system, mannose-specific IIABCD components, transport and binding proteins, flagella synthesis-related proteins, a transcriptional regulator, and hypothetical proteins. The gene expression changes determined by microarray assays were confirmed by the real-time RT-PCR analyses [60]. This study highlights the importance of CtsR in pressure tolerance and will contribute to the appropriate design of safe, effective, and feasible high hydrostatic pressure (HHP) treatments.

In addition to microarrays, other genomic technologies have been used to study food-borne pathogens and food-related bacteria. For example, in vivo expression technology (IVET) was used to identify Lactobacillus sakei genes that were induced during meat fermentation [61]. Real-time PCR assays were used to study the spores of Bacillus anthracis Sterne strain under different interventions such as heat, pasteurization, and microfiltration. Genes related to spore germination and sporulation have been identified. These genes could
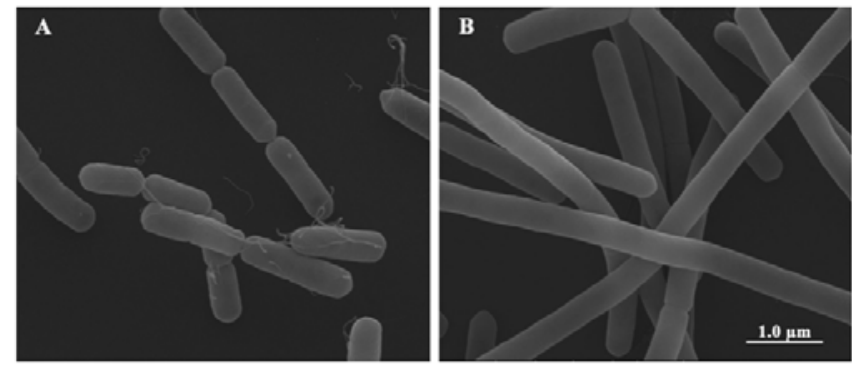

Figure 3: Morphological characteristics of exponentially grown cells of $L$. monocytogenes Scott A wild type (A) and mutant (2-1) with scan electron microscope (SEM). Bars, $1 \mu \mathrm{m}$. Adapted from Liu et al. [60] with permission. 
serve as biomarkers for pasteurization and microfiltration [62]. These approaches can complement microarray assays and provide more information on bacterial survival in food environments.

\section{Conclusions and Future Perspectives}

Microarrays hold promise for food safety applications. To make microarrays more practical for use with food samples, we face the challenge of isolating sufficient amounts of bacterial DNA or RNA from food and improving the fluorescent labeling of target DNA or CDNA so that we can reduce the requirement for micrograms of RNA or DNA to nanogram levels. Although amplification of RNA and DNA has been successfully developed $[21,22,36]$ these approaches are mainly limited to pure cultures. Additional work is needed to improve the sensitivity and specificity before these approaches can be used in food samples. Since microarray analysis also suffers from problems associated with reproducibility, reliability, compatibility and standardization of results [63], it is usually confirmed by a complementary platform such as real-time PCR assays. The high costs of reagents (microarray chip and labeling kits) and of instruments (scanner and hybridization chambers) also limit the use of microarrays in food safety. More efforts should be directed toward making detection microarrays affordable so that they can be routinely used in food safety. Another important area in microarray is data analysis. In food industry setup, high-level data analysis and proper interpretation could potentially lead to an identification of targets for interventions.

In gene expression studies, microarrays are limited to microorganisms whose genomes have been fully sequenced and characterized. In addition, microarrays only limit expression studies to the level of RNA, but do not allow distinction between de novo synthesized transcripts and modified transcripts. Given these limitations, microarrays are now being superseded by transcriptomics based on next-generation sequencing technologies [64]. In the future, microarrays should be used together with other emerging approaches such as next-generation sequencing technologies, thus can provide complete pictures of food-borne pathogens in food.

\section{Acknowledgments}

The author would like to thank Drs. Pina Fratamico, John B. Luchansky, and James Smith (USDA, Agricultural Research Services, Eastern Regional Research Center, Wyndmoor, PA) for critical reading of the manuscript and helpfu discussions

\section{References}

1. Brul S, Schuren F, Montijn R, Keijser BJF, van der Spek H, et al. (2006) The impact of functional genomics on microbiological food quality and safety. Int $J$ Food Microbiol 112: 195-199.

2. Bodrossy L, Sessitsch A (2004) Oligonucleotide microarrays in microbial diagnostics. Curr Opin Microbiol 7: 245-254.

3. Kostrzynska M, Bachand A (2006) Application of DNA microarray technology for detection, identification, and characterization of food-borne pathogens. Can $\mathrm{J}$ Microbiol 52: 1-8.

4. Liu-Stratton Y, Roy S, Sen C K (2004) DNA microarray technology in nutraceutical and food safety. Toxicol Lett 150: 29-42.

5. Spielbauer B, Stahl F (2005) Impact of microarray technology in nutrition and food research. Mol Nutr Food Res 49: 908-917.

6. Wendisch VF, Zimmer DP, Khodursky A ,Peter B, Cozzarelli N, et al.(2001) Isolation of Escherichia coli mRNA and comparison of expression using mRNA and total RNA on DNA microarrays. Anal Biochem 290: 205-13.

7. Knapen D, Vergauwen L, Laukens K, Blust R (2009) Best practices for hybridization design in two-colour microarray analysis. Trends Biotechnol 27 406-414

8. Al-Khaldi SF, Martin SA, Rasooly A, Evans JD (2002) DNA microarray technology used for studying foodborne pathogens and microbial habitats: minireview. J AOAC Int 85: 906-10

9. Sergeev N, Distler M, Courtney S, Al-Khaldi SF, Volokhov D, et al. (2004) Multipathogen oligonucleotide microarray for environmental and biodefense applications. Biosens Bioelectron 20: 684-698.

10. Call DR, Borucki MK, Loge FJ (2003) Detection of bacterial pathogens in environmental samples using DNA microarrays. J Microbiol Methods 53: 235243

11. Kakinuma K, Fukushima M, Kawaguchi R (2003) Detection and identification of Escherichia coli, Shigella, and Salmonella by microarrays using the gyrB gene. Biotechnol Bioeng 83: 721-728.

12. Chizhikov V, Rasooly A, Chumakov K, Levy DD (2001) Microarray analysis of microbial virulence factors. Appl Environ Microbiol 67: 3258-3263.

13. Wilson WJ, Strout CL, DeSantis TZ, Stilwell JL, Carrano AV, et al.(2002) Sequence-specific identification of 18 pathogenic microorganisms using microarray technology Mol Cell Probes 16: 119-127.

14. Borucki MK, Krug MJ, Muraoka WT, Call DR (2003) Discrimination among Listeria monocytogenes isolates using a mixed genome DNA microarray. Vet Microbiol 92: 351-362.

15. Borucki MK, Kim SH, Call DR, Smole SC, Pagotto F (2004) Selective discrimination of Listeria monocytogenes epidemic strains by a mixed-genome DNA microarray compared to discrimination by pulsed-field gel electrophoresis, ribotyping, and multilocus sequence typing. J Clin Microbiol 42: 5270-5276.

16. Alvarez J, Porwollik S, Laconcha I, Gisakis V, Vivanco AB, et al. (2003) Detection of a Salmonella enterica serovar California strain spreading in spanish feed mills and genetic characterization with DNA microarrays. App Environ Microbiol 69:7531-7534.

17. Zhou J, Thompson DK (2002) Challenges in applying microarrays to environmental studies. Curr Opin Biotechnol 13: 204-207.

18. Stevens KA, Jaykus LA (2004) Bacterial separation and concentration from complex sample matrices: a review. Crit Rev Microbiol 30: 7-24.

19. Liu Y, Fratamico P (2006) Escherichia coli O antigen typing using DNA microarrays. Mol Cell Probes 20: 239-244.

20. Luthra R, Medeiros LJ (2004) Isothermal multiple displacement amplification: a highly reliable approach for generating unlimited high molecular weigh genomic DNA from clinical specimens. J Mol Diagn 6: 236-242.

21. Dean FB, Hosono S, Fang L, Wu X, Faruqi AF, et al. (2002) Comprehensive human genome amplification using multiple displacement amplification. Proc Natl Acad Sci U S A. 99: 5261-5266.

22. Wu L, Liu X, Schadt CW, Zhou J (2006) Microarray-based analysis of subnanogram quantities of microbial community DNAs by using wholecommunity genome amplification. Appl Environ Microbiol 72: 4931-4941.

23. Bozdech Z, Zhu J, Joachimiak MP, Cohen FE, Pulliam B, et al. (2003) Expression profiling of the schizont and trophozoite stages of Plasmodium falciparum with a long-oligonucleotide microarray. Genome Biol 4: R9.

24. Draghici S, Khatri P, Liu,Y, Chase KJ, Bode EA, et al. (2005) Identification of genomic signatures for the design of assays for the detection and monitoring of Anthrax threats. Pac Symp Biocomput 248-259.

25. Tembe W, Zavaljevski N, Bode E, Chase C, Geyer J, et al. (2007) Oligonucleotide fingerprint identification for microarray-based pathogen diagnostic assays. Bioinformatics 23: 5-13.

26. Vijaya Satya R, Zavaljevski N, Kumar K, Bode E, Padilla S, et al. (2008) In silico microarray probe design for diagnosis of multiple pathogens. BMC Genomics 9: 496.

27. Vijaya Satya R, Zavaljevski N, Kumar K, Reifman J (2008) A high-throughput pipeline for designing microarray-based pathogen diagnostic assays. BMC Bioinformatics 9: 185.

28. DebRoy C, Fratamico PM, Roberts E, Davis MA, Liu Y (2005) Developmen of PCR assays targeting genes in O-antigen gene clusters for detection and identification of Escherichia coli $\mathrm{O} 45$ and $\mathrm{O} 55$ serogroups. Appl Environ Microbiol 71: 4919-4924

29. Fratamico PM, Briggs CE, Needle D, Chen CY, DebRoy C (2003) Sequence 
Citation: Liu Y, Wang Y, Gang J (2011) Challenges of microarray applications for microbial detection and gene expression profiling in food. J Microbial Biochem Technol S2:001. doi:10.4172/1948-5948.S2-001

of the Escherichia coli 0121 O-antigen gene cluster and detection of enterohemorrhagic $E$. coli 0121 by PCR amplification of the wzx and wzy genes. J Clin Microbiol 41: 3379-3383.

30. Liu Y, DebRoy C, Fratamico PM (2007) Sequencing and analysis of the Escherichia coli serogroup 0117, O126, and $0146 \mathrm{O}$ antigen gene clusters and development of PCR assays targeting serogroup O117-, O126-, and 0146-specific DNA sequences. Mol Cell Probes 21: 295-302.

31. Liu Y, Fratamico PM, DebRoy C, Bumbaugh AC, Allen JW (2008) DNA sequencing and identification of serogroup-specific genes in the Escherichia coli $\mathrm{O} 118 \mathrm{O}$ antigen gene cluster and demonstration of antigenic diversity but only minor variation in DNA sequence of the $\mathrm{O}$ antigen clusters of $\mathrm{E}$. coli $\mathrm{O} 118$ and 0151. Foodborne Pathog Dis 5: 449-457.

32. Fratamico PM, DebRoy C, Miyamoto T, Liu Y (2009) PCR detection of enterohemorrhagic Escherichia coli O145 in food by targeting genes in the $\mathrm{E}$. coli 0145 O-Antigen gene cluster and the Shiga Toxin 1 and Shiga Toxin 2 genes. Foodborne Patho Dis 6: 605-611.

33. Abee T, van Schaik W, Siezen RJ (2004) Impact of genomics on microbial food safety. Trends Biotechnol 22: 653-660.

34. Budde I, Steil L, Scharf C, Völker U, Bremer E (2006) Adaptation of Bacillus subtilis to growth at low temperature: a combined transcriptomic and proteomic appraisal. Microbiology 152: 831-853.

35. Chan YC, Raengpradub S, Boor KJ, Wiedmann M (2007) Microarray-based characterization of the Listeria monocytogenes cold regulon in log- and stationary-phase cells. Appl Environ Microbiol 73: 6484-6498.

36. Gao H, Yang ZK, Gentry TJ, Wu L, Schadt CW, et al. (2007) Microarray-based analysis of microbial community RNAs by whole-community RNA amplification. Appl Environ Microbiol 73: 563-571.

37. Liu Y, Ream A (2008) Gene expression profiling of Listeria monocytogenes strain F2365 during growth in ultrahigh-temperature-processed skim milk. App Environ Microbiol 74: 6859-6866.

38. Duodu S, Mehmeti I, Holst-Jensen A, Loncarevic S (2009) Improved sample preparation for real-time PCR detection of Listeria monocytogenes in hotsmoked salmon using filtering and immunomagnetic separation techniques. Food Analytical Methods 2: 23-29.

39. Duodu S, Holst-Jensen A, Skjerdal T, Cappelier JM, Pilet MF, et al. (2010) Influence of storage temperature on gene expression and virulence potential of Listeria monocytogenes strains grown in a salmon matrix. Food Microbiol 27: $795-801$

40. Olesen I, Thorsen L, Jespersen L (2010) Relative transcription of Listeria monocytogenes virulence genes in liver pâtés with varying $\mathrm{NaCl}$ content. Int $\mathrm{J}$ Food Microbiol 141: S60-S68

41. Duquenne M, Fleurot I, Aigle M, Darrigo C, Borezée-Durant E, et al. (2010) Tool for quantification of staphylococcal enterotoxin gene expression in cheese. Appl Environ Microbiol 76: 1367-1374.

42. Enfors SO, Jahic M, Rozkov A, Xu B, Hecker M, et al. (2001) Physiological responses to mixing in large scale bioreactors. J Biotechnol 85: 175-185.

43. Nelson KE, Fouts DE, Mongodin EF, Ravel J, DeBoy RT, et al. (2004) Whole genome comparisons of serotype $4 b$ and $1 / 2 a$ strains of the food-borne pathogen Listeria monocytogenes reveal new insights into the core genome components of this species. Nucleic Acids Res 32: 2386-2395.

44. Postier B, Didonato R Jr, Nevin KP, Liu A, Frank B, et al. (2008) Benefits of in-situ synthesized microarrays for analysis of gene expression in understudied microorganisms. J Microbiol Methods 74: 26-32.

45. Weckx S, Van der Meulen R, Allemeersch J, Huys G, Vandamme P, et al (2010) Community dynamics of bacteria in sourdough fermentations as revealed by their metatranscriptome. Appl Environ Microbiol 76: 5402-5408.

46. Kyle JL, Parker CT, Goudeau D, Brandl MT (2010) Transcriptome analysis of Escherichia coli O157:H7 exposed to lysates of lettuce leaves. Appl Environ Microbiol 76: 1375-1387.

47. Azcarate-Peril MA, Tallon R, Klaenhammer TR (2009) Temporal gene expression and probiotic attributes of Lactobacillus acidophilus during growth in milk. J Dairy Sci 92: 870-886

48. Smeianov VV, Wechter P, Broadbent JR, Hughes JE, Rodríguez BT, et al (2007) Comparative high-density microarray analysis of gene expression during growth of Lactobacillus helveticus in milk versus rich culture medium. Appl Environ Microbiol 73: 2661-2672.
49. Gitton C, Meyrand M, Wang J, Caron C, Trubuil A, et al. (2005) Proteomic signature of Lactococcus lactis NCDO763 cultivated in milk. Appl Environ Microbiol 71: 7152-7163.

50. Hufner E, Markieton T, Chaillou S, Crutz-Le Coq AM, Zagorec M, et al. (2007) Identification of Lactobacillus sakei genes induced during meat fermentation and their role in survival and growth. Appl Environ Microbiol 73: 2522-2531.

51. Bowman JP, Bittencourt CR, Ross T (2008) Differential gene expression of Listeria monocytogenes during high hydrostatic pressure processing. Microbiology 154: 462-475.

52. Ishii A, Oshima T, Sato T, Nakasone K, Mori H, et al. (2005) Analysis of hydrostatic pressure effects on transcription in Escherichia coli by DNA microarray procedure. Extremophiles 9: 65-73.

53. Malone AS, Chung YK, Yousef AE, (2006) Genes of Escherichia coli O157:H7 that are involved in high-pressure resistance. Appl Environ Microbiol 72: 2661 2671

54. Nair S, Derré I, Msadek T, Gaillot O, Berche P (2000) CtsR controls class III heat shock gene expression in the human pathogen Listeria monocytogenes. Mol Microbiol 35: 800-811.

55. Krüger E, Zühlke D, Witt E, Ludwig H, Hecker M (2001) Clp-mediated proteolysis in Gram-positive bacteria is autoregulated by the stability of a repressor. EMBO J 20: 852-863.

56. Karatzas KA, Bennik MH (2002) Characterization of a Listeria monocytogene Scott $A$ isolate with high tolerance towards high hydrostatic pressure. App Environ Microbiol 68: 3183-3189.

57. Karatzas KA, Wouters JA, Gahan CG, Hill C, Abee T, et al. (2003) The CtsR regulator of Listeria monocytogenes contains a variant glycine repeat region that affects piezotolerance, stress resistance, motility and virulence. Mo Microbiol 49: 1227-1238

58. Karatzas KA, Valdramidis VP, Wells-Bennik MH, (2005) Contingency locus in ctsR of Listeria monocytogenes Scott A: a strategy for occurrence of abundan piezotolerant isolates within clonal populations.Appl Environ Microbiol 71: 8390-8396.

59. Joerger RD, Chen H, Kniel KE (2006) Characterization of a spontaneous pressure-tolerant Listeria monocytogenes Scott A ctsR deletion mutant. Foodborne Pathog Dis 3: 196-202.

60. Liu Y, Ream A, Joerger RD, Liu J, Wang Y (2011) Gene expression profiling of a pressure-tolerant Listeria monocytogenes Scott A ctsR deletion mutant. J Ind Microbiol Biotechnol 38: 1523-1533.

61. Hufner E, Markieton T, Chaillou S, Crutz-Le Coq AM, Zagorec M, et al. (2007) Identification of Lactobacillus sakei genes induced during meat fermentation and their role in survival and growth. Appl Environ Microbiol 73: 2522-2531.

62. Liu Y, Ream A (2009) Sporulation and germination gene expression analysis of Bacillus anthracis Sterne spores in skim milk under heat and different intervention techniques. J Food Sci 74: M120-M124.

63. Wang Y, Barbacioru C, Hyland F, Xiao W, Hunkapiller KL, et al. (2006) Large scale real-time PCR validation on gene expression measurements from two commercial long-oligonucleotide microarrays. BMC Genomics 7: 59.

64. van Vliet $\mathrm{AH}$ (2010) Next generation sequencing of microbial transcriptomes: challenges and opportunities. FEMS Microbiol Lett 302: 1-7. 